\title{
A ação de educar como rito de iniciação à ética da coexistência
}

Ama a humanidade como a ti mesmo! Isso é tudo e nada mais é preciso.

Dostoiévski
Miguel Almir Lima de Araújo Professor da UNEB e da UEFS malmir@uol.com.br

\begin{abstract}
RESUMO: O texto medita acerca da supremacia dos paradigmas da racionalidade calculista e tecnico-cietífica em nosso processo civilizatório que, desprovidos dos repertórios da Ética, incidem em posturas separatistas e dilapidadoras. Aborda a Ética como o cuidado com a morada do humano, com os valores humanos. Trata da Ética da coexistência plasmada no desvelo com as relações entre os seres humanos e destes com todos os seres do universo: a eco-ética. Compreende a ação de educar como rito vivo de iniciação aos valores humanos, ao cuidado com a auto-ética e a eco-ética: a Ética da coexistência fomentando relações mais fraternas e solidárias, amorosas e interdependentes na afinação da compaixão do coração e do humanismo do espirito.
\end{abstract}

PALAVRAS-CHAVE: Ação educativa. Ética. Educação humanística. Valores humanos

\section{O eclipse da ética em nosso cotidiano}

Tecer relações de coexistência inspiradas nos princípios da solidariedade e da fraternidade, da eqüidade e da amorosidade tem sido um dos aprendizados mais difíceis e desafiantes para a nossa raça humana.

Os paradigmas que exercem supremacia em nosso processo civilizatório privilegiam as lógicas instrumentais, os valores produtivistas e consumistas que promovem a competição e o individualismo autofágicos e que desembocam em posturas fragmentadoras e mutiladoras da dinâmica das relações sociais e ecossistêmicas.

Esses processos incidem em separatismos forjadores de posturas excêntricas de intolerância e de odiosidade que embargam e esfiapam a rede das relações de cooperação e de humanização entre os sujeitos humanos. Dessa forma, a teia viva da coexistência, da convivência humana fica desfigurada e dilapidada.

Nessa perspectiva, superestimamos o saber, a técnica, o ter, e negligenciamos o aprendizado da sabedoria, dos valores humanos, 
do ser. O conhecimento desprovido dos conteúdos da consciência, da postura ética, como flagramos em diversos momentos e fenômenos no cotidiano da história, converte-se em instrumento de tirania, de cinismo, de iniqüidade.

Aprendemos muito sobre muita coisa; construímos arsenais imensuráveis de conhecimento técnico, científico e erudito; dominamos muitos recursos tecnológicos sofisticados de natureza funcional e pragmática. Detemos muito poder sobre os instrumentos externos, dos papéis e máscaras externas. Porém, ficamos ignorantes e esvaziados no que se refere aos domínios internos do ser, no trato com as coisas humanas, com a condição humana, com as relações de coexistência. Parece que não aprendemos ainda a cuidar com mais desvelo da convivência humana solidária e fraterna, da morada acolhedora e comum do humano. Ficamos empanturrados de saber e esfomeados de sabedoria.

O mundo contemporâneo tem sido marcado por um profundo mal estar nas esferas das estruturas e das práticas sociopolíticas e culturais. Os ideais de progresso e de felicidade para toda a humanidade, propagados pelo Iluminismo, parecem ter se desmanchado pelos ermos dos ares. Os expressivos avanços e descobertas científicas, a sofisticação dos recursos tecnológicos, por um lado, trouxeram contribuições relevantes e grandiosas para o bem da humanidade. Mas, por outro lado, e com significativa predominância desta instância, levou as sociedades humanas e o ecossistema a estados violentos de degradação e de esgarçamento.

Desprovidos das fontes primordiais dos valores humanos que estruturam a consciência e a postura éticas, os seres humanos são reduzidos ao âmbito zoológico do existir em que prevalecem seus instintos primários. A confinação da vida humana às esferas instintivas e materiais converte os humanos em meros animais selvagens que passam a competir e a se digladiar uns com os outros impelidos pela lei dos mais fortes - a "lei de Gerson".

Esvaziados da sensibilidade Ética, os indivíduos se brutalizam, se auto e inter destroem uns aos outros, exilam-se de sua morada humana edificando cárceres aprisionantes. A ausência do cuidado com a Ética encerra os mesmos em atitudes que representam sua hostilidade primária, sua condição animal mais incipiente e tosca. Sua condição humana fica desertificada e congelada. Essa hostilidade primária inflada leva às atitudes e posturas insanas e predatórias. 
A desfiguração da Ética, que avassala nossa cultura e macula a paisagem humana, nos atola no imundo; enfeia o mundo. Numa sociedade em que a dignidade humana é denegada e dilapidada, os humanos são esvaziados de sua condição humana primordial e passam, assim, a ser coisificados e mercadejados como bens utilitários e consumíveis em processos hostis de desumanziação. O ser se converte em objeto, em máquina, na histeria da consumação do ter, através dos modelos socioeconômicos excludentes e perversos. Dessa forma, os frutos da civilização se desdobram numa civilização barbárica, numa "barbárie civilizóide" - uma neobarbarização - com a depredação de todo o ecossistema.

A perda do espírito de indignação diante dos fatos e estruturas, que vilipendiam e aprisionam o ser humano, se traduz na indiferença glacial, no cinismo cortante. Um ser que não mais se comove diante da opressão, da fome, do espezinhamento apagou em si mesmo a chama da generosidade, do altruísmo, do amoroso. Diskin (1998, p. 76) afirma: "A indiferença, o cinismo, o ceticismo, o deboche são a cegueira absoluta que abrem espaços para o surgimento de totalitarismos, fanatismos, fundamentalismos e xenofobias".

Uma outra característica de desfiguração da Ética é a tendência de imposição de modelos únicos, de posturas homogeneizantes pelos poderes instituídos que elegem um quadro de referência como centro, como verdade única, em detrimento das expressões das diferenças, da heterogeneidade dos modos de ser e de estar no mundo, da pluralidade de valores que constituem a teia mestiça da cultura humana. Os modelos e posturas monológicas se projetam, de modo autocrático e intolerante, recalcando e denegando a presença da pluralidade dos modos de expressão dos sentidos humanos nas mais diversas práxis socioculturais. Esses poderes uniformizantes procuram se apropriar e controlar o diferente para subjugá-lo.

Os modelos patriarcais que predominam em nossa tradição cultural, bem como os totalitarismos políticos e econômicos são quadros bastante ilustrativos dos processos de intolerância, de segregação e de exclusão das diferenças de valores, de crenças, de gênero, de condição social; dos processos de encarceramento do humano. São quadros que representam processos fundamentalistas de homogeneização e de uniformização excludentes com a supremacia do monólogo autocrático que elege um grupo, 
um modelo ou ideologia como centro e que desqualifica o que é diverso como periférico, como impertinente.

O eclipse da Ética nos contextos de nossas relações sociais cotidianas desbota a fisionomia do humano, depreda a teia entrelaçada do ecossistema. Os descuidos para com a teia das relações de coexistência, a predominância de paradigmas mecanicistas e segregacionistas foi nos barbarizando e nos expondo a condições de vida tão dramáticas que todo planeta terra se encontra ameaçado. Vivemos um tempo de crises desmedidas que nos interpelam para desafios ingentes. Desafios que implicam em mudanças profundas em nossos valores e posturas.

São tempos crísico-seminais que apontam para processos prementes de transformações que vislumbrem a re-humanização de nossa presença no planeta, mediante a instituição de modos de relações intersubjetivas/sociais e ecológicas fundadas na Ética da coexistência solidária inspirada nos valores da fraternidade, da eqüidade e da amorosidade - do Ecohumanismo.

\section{Os sentidos da ética}

Para recuperar nossa plena humanidade, temos de recuperar nossa experiência de conexidade com toda a teia da vida. Fritjof Capra

A expressão grega éthos é portadora de um núcleo referencial semântico de grande relevância para a compreensão dos universos/pluriversos culturais que consubstanciam a vida dos seres humanos na cotidianidade de seus contextos históricos. Éthos, em seu sentido mais estrito, designa hábito, costume e modo de vida; o universo de valores e de crenças que compõem a teia viva da cultura dos indivíduos em seus contextos históricos mais singulares e plurais.

Desse modo, o éthos se configura como lastro de referências que traduz os valores e sentidos que constituem as dimensões mais radicais (de raiz) da cultura de um povo. O éthos se processa e se projeta nos meandros mais fundos e recurvados do imaginário dos indivíduos, mediante dimensões mais inconscientes e até invisíveis que se materializam no estofo das ações vividas cotidianamente. É a seiva que dá vigor e faz vicejar a árvore da vida de cada indivíduo 
em seus laços coexistenciais. Seiva que é nutrida nas fontes originárias das tradições culturais de cada grupo/comunidade/povo.

Os repertórios da tradição que estão sedimentadas no éthos são constituídos de elementos vivos e dinâmicos, de tesouros simbólicos e mitopoéticos originários que configuram a existência e a coexistência de um povo. É um manancial de sabedorias tecidas na trajetória das travessias dos indivíduos humanos pelos vãos e desvãos de suas vivências no mundo.

Na morada da Phýsis, dos seres da natureza, tudo é dado a priori. Os seres e fenômenos naturais, no fluxo de seus ciclos cósmicos, são originados e constituídos pelos desígnios da própria natureza intrínseca de cada ser. Na morada do éthos, tudo é construído pelos seres humanos em suas trajetórias histórico-culturais. Ela é plasmada a partir do dinamismo dos repertórios simbólicos que constituem as práxis humanas com seus traços singulares. É erigida pelos valores que os indivíduos recebem (tradição) e pelos que os mesmos criam e recriam, inventam e inauguram na teia viva e in-tensiva das relações sociais em cada momento histórico específico.

O Éthos, nessa perspectiva, se constitui como tradição (VAZ, 1993), ou seja, representa a "riqueza simbólica" que os indivíduos criam e que, de forma dinâmica, é transmitida para as novas gerações. Estas, conseqüentemente, se inspiram nesses tesouros simbólicos e os renovam nas curvas do tempo vivido/vivente. Assim, na história humana, o éthos é configurado pelos repertórios que estampam os símbolos da cultura marcados pelos seus valores multicores. São as marcas do éthos que tecem e entretecem o tecido policrômico da cultura.

O cuidado com o Éthos, com a Ética, representa o zelo pela habitação humana, pela morada do humano, pelo modo com que nos relacionamos uns com os outros dentro dessa casa. Esse cuidado se traduz na busca de uma atmosfera arejada e aprazível que revela simpatia e cordialidade nos influxos nas relações sociais; ocorre na proporção em que as mesmas se tornam mais solidárias e amorosas, mais justas e livres; em que cultivamos a busca da paz e do bem comum.

Para os gregos, notadamente para Aristóteles (1987), a Ética, no cenário das relações humanas, trata da justa medida, do caminho do meio, traduzindo-se este na atitude sábia que ultrapassa os excessos e que busca a realização das virtudes do bem, da justi- 
ça, da eqüidade. A presença da Ética torna-se curativa, no seio do convívio humano, na medida em que proporciona o cuidado com o bom senso, com ações e posturas cuidadosas no trato com o humano, com a teia das relações humanas. A Ética se constitui, portanto, como o cuidado primoroso para com a justiça, para com o bem, para com as atitudes virtuosas na teia das inter-relações humanas.

$\mathrm{Na}$ tradição de nosso processo civilizatório, a Ética passou a ser concebida como "teoria da ação" (VAZ, 1993) que apresenta princípios universais norteadores da práxis humana. Aristóteles (1987) identifica a Ética como a "Teoria da ação justa", sendo, portanto, caracterizada pela razão prática, pela práxis que conjuga lastro teórico e vivência: a phronesis grega que representa a sabedoria prática, ou seja, a ação encarnada no cotidiano e iluminada pela ponderação e pelo discernimento sábio do espírito.

Para Aristóteles (1987), o propósito fundamental da Ética é proporcionar a felicidade humana - a eudaimonia. Na proporção em que conduzimos nossas ações inspiradas nos valores do bem, da justiça, da justa medida, da temperança, podemos atingir o estado de felicidade que irradia o espírito e o corpo humanos.

Os artefatos da técnica - atinentes à lógica, ao homo faber devem ser concebidos como meios, como instrumentos operativos que devem ser utilizados e aplicados a serviço de fins, de princípios fundantes - o ontológico, o homo sapiens. Os meios - os recursos do ter - viabilizam o modus operandi que enredam e processualizam a realização dos fins, dos valores últimos que constituem e dignificam a condição humana. Valores que proporcionam a eudaimonia, a felicidade humana que vivifica o ser, na esfera de seus limites e possibilidades. A Ética se desdobra no aprendizado e na práxis do saber ser, do ser-com-os-outros no cotidiano vivido.

A práxis ética se norteia pela relação dialógica de implicação com a diversidade de valores que constitui os indivíduos e grupamentos humanos. É o elo de ligação que interliga as singularidades e as diferenças proporcionando relações in-tensivas de trocas mútuas em que a escuta do outro se torna presente. Escuta despojada em que os indivíduos se conflituam de modo aberto, solidário e criativo, e podem, assim, compreender que as diferenças potencializam as relações trazendo aprendizados recíprocos e expansivos. Desse modo, percebemos melhor os limites e 
as possibilidades que medeiam as relações, ultrapassando as posturas ortodoxas e sectárias que segregam e bestializam.

A consciência ética instala-se na compreensão de que a condição humana é constituída de interdependência e de complementaridade entre todos os humanos, nos mais diversos modos de relações e de experiências bio-socioculturais. Assim, as posturas e atitudes humanas impregnadas de individualismo, de egoísmo excêntrico, em que os indivíduos entram em processos hostis de competição, de servilização e de exclusão, são descaracterizadoras da Ética. A práxis ética, fundamentalmente, se plasma na teia entrelaçada das inter-relações em que os cidadãos e cidadãs compartilham suas identidades e diferenças, suas singularidades e pluralidades, bem como os desafios e ambigüidades os paradoxos - da condição humana.

Os valores das tradições culturais mais locais, com suas singularidades e características próprias, como repertórios que traduzem as identidades culturais híbridas de cada grupamento humano, com suas crenças, sentimentos e cosmovisões, se constituem em elementos fundamentais nos territórios da Ética. Assim, podem se estabelecer os vínculos dialógicos com os conteúdos culturais mais diversificados e universais, buscando-se entre o local e o global, relações dinâmicas e in-tensivas de trocas e de inter-relações alargantes - o glocal.

$\mathrm{Na}$ trama da cultura que traduz a complexidade do humano, a práxis ética é movida pelas tensões e pelas incertezas atinentes à mesma. As interpolaridades que imbricam caos (desordem) e cosmos (ordem) impulsionam os meandros das relações sociais e potencializam a sedimentação da Ética mediante os processos de dinamização dos fluxos tensoriais que constituem as trajetórias humanas, que fomentam os influxos de coexistência.

Sem a presença da Ética, as relações sociais, as experiências políticas que traduzem a articulação do coletivo se esvaziam e se degradam. A cidadania se materializa na medida em que os princípios da Ética lastreiam nossas ações cotidianas. O político, como instância do cuidado com o bem comum, do tecer de forma justa e solidária as relações sociais, se processa de modo digno quando prima efetivamente pela eqüidade, pelo bem comum - pela cepa da Ética. 


\section{A ética da coexistência}

A religação deve substituir a disjunção

e apelar à 'simbiosofia', a sabedoria de viver junto.

Edgar Morin

Para que o cuidado com a Ética se torne princípio norteador nas ações humanas, torna-se imprescindível a práxis dialógica, a pedagogia do diálogo como instância que proporciona relações de trocas e de aprendizados mútuos entre as diferenças. Mediante as relações dialógicas fundadas na abertura, na dis-posição do espírito e do coração, na complexidade enriquecedora das diferenças culturais, étnicas, religiosas, etc, os seres humanos podem compartilhar suas crenças, seus sentimentos e valores na perspectiva de sedimentar relações mais fraternas e solidárias, mais humanizantes e ecohumanizantes.

A abertura para os fluxos dialógicos entre as diversidades pressupõe a superação dos egoísmos asfixiantes que redundam em individualismos suicidas. Pressupõe a busca do ecoísmo em que aprendemos a tecer os laços que compõem a rede in-tensiva e multicor da teia do humano; em que as estampas das diferenças podem embonitar os laços que entrelaçam os abraços eivados de solidariedade e de compaixão. O ecoísmo se traduz na procura de relações de acolhimento entre todos os seres humanos e destes com todos os seres do universo. Juntos, somos como instrumentos de uma orquestra que, na peculiaridade de cada um e na interligação entre todos, compomos a inteireza polifônica da sinfonia cósmica no ritmo da "harmonia conflitual".

Essa perspectiva ecoísta desemboca no Ecohumanismo em que o ser humano não é mais concebido como centro do universo, como ser onipotente, onipresente e onisciente. Ele é concebido com a magnitude se seu ser singular no planeta Terra, porém, não mais como centro único, nem absoluto, e sim, como partícula que compartilha e coexiste com milhões de outros seres, em que todos são relevantes em suas singularidades, na tessitura da teia viva do ecossistema planetário, de modo policêntrico, ecocêntrico.

O Ecohumanismo revela o cuidado com a eco-ética em que os seres humanos, com sua consciência sensível e aprendente, pode 
compreender o movimento da dinâmica viva e coexistente, e, portanto, interdependente e complementar que existe entre todos os seres do universo. Desse modo, as relações de cada um consigo mesmo - a auto-ética -, como também, com todos os seres - a eco-ética -, passam a ser afirmadoras dos valores do cuidado, da compaixão, da cooperação, do respeito e da admiração para com a riqueza e para com a beleza da teia híbrida e co-movente do ecossistema.

A eco-ética se processa na proporção em que investimos na auto-ética como condição sine qua non para que aquela se presentifique. A auto-ética se materializa em nosso afinco na busca do autoconhecimento, do conhece-te a ti mesmo, em que procuramos compreender nossos limites e nossas possibilidades, nossa grandeza e nossa pequenez, nosso demens e nosso sapiens; em que cuidamos com mais primor de nossos sentimentos e emoções, das qualidades preciosas dos valores humanos.

O trato com a auto-ética incide na superação dos fossos que nos separam de nós mesmos, que separam nossas palavras de nossas atitudes, nosso dentro de nosso fora. Supõe uma relação de honestidade (on - todo, inteiro), de autenticidade e de implicação dinâmica e fecunda entre as dimensões que compõem a globalidade de nosso ser e de nossa relação despojada e sincera com os outros.

Para ultrapassarmos o estado de barbarização em que está mergulhada a cultura e a sociedade em nosso mundo contemporâneo - barbárie que revela o flagrante descuido para com a autoética e a eco-ética -, urge investirmos nos processos de religação daquilo que tanto separamos. Religar o corpo com a mente, a razão com a intuição, o masculino com o feminino, o espírito com o coração; enfim, a ética com a estética - instâncias conjuntamente constitutivos da inteireza do humano. Podemos ter atitudes bastante justas e dignas no campo da Ética, porém, se nos faltam a sensibilidade e a delicadeza da estética, podemos nos tornar insípidos e carrancudos.

A barbárie é, principalmente, conseqüência do predomínio dos valores e posturas segregativas que desembocam nas intolerâncias e nas competições medonhas para a cultura humana e para todo o ecossistema vivo. Em nossas relações, tem prevalecido o espírito diabólico - diabolus, diaballein - (MORIN, 1998; BOFF, 1999) que separa, mutila e, conseqüentemente, provoca atrocidades e destrutividades. Ultrapassar a predominância dos paradigmas 
que priviligiam o diaballein na instauração de posturas inspiradas no religare, no symballein (simbólico - o que une) parece ser um rumo ingente e imprescindivel para tecermos referências, aprendizados e atitudes éticas fecundas - a auto-ética e a eco-ética - a Ética da religação, da implicação e da coexistência.

A Ética da coexistência, da solidariedade traduz-se numa poética impregnada de sensibilidade que interliga razão e coração, o si mesmo e o outro, pensamento e sentimento - uma antro-poética em que o cuidado com o humano, com o ser humano é tecido e bordado com primor em direção à eco-ética. A eco-ética, como vimos, se descortina no desvelo com a teia interdependente e complementar das relações entre todos os seres do ecossistema vivo. A vivência da Ética da coexistência também incide no cuidado com a biodiversidade, com os diversos seres e espécies constituintes desse ecossistema vivo em que co-pertencemos. Como explicita Morin (1999, p. 133): "Só podemos respeitar verdadeiramente a vida humana se respeitamos, ao máximo, a vida em geral" nos processos de co-pertencimento planetário.

O sábio Yaqui D. Juan desborda: Um caminho sem coração se volta contra os homens e os destrói. A Ética da coexistência carece do olhar crítico, alargado e compreensivo do pensamento meditativo/reflexivo que dialoga, aberta e sabiamente, com os mistérios da cordialidade do coração, numa dialogia que entrelaça a compaixão do coração e o humanismo do espírito (Morin). Dessa forma, podemos trilhar os compassos da busca da sabedoria que nos conduz ao esprit de finesse, à fineza do ser.

A vivência da Ética da coexistência se revela, de modo fecundo, na imagem-símbolo do abraço que entrelaça os indivíduos na singularidade de cada diferença, compondo assim, a roda heterogênea da unidade e da multiplicidade dos seres - a unitas multiplex -, do universo/pluriverso. Roda que nos dispõe abertamente para o encontro com os outros, com o olhar dos outros, no acolhimento despojado do abraço que une e complementa os diversos irradiando o arco da solidariedade, da tolerância, da partilha, do reconhecimento do outro: laço alargado e in-tensivo que floreja o abraço grandioso que fra-terniza e vivifica o humano.

A eco-ética ultrapassa a postura antropocêntrica e se deslancha na postura ecocêntrica em que não existe mais centro determinista, mas instâncias entrelaçadas de uma grande roda; um grande círculo em que a circunferência está em todas as par- 
tes e em nenhum lugar. Dessa forma, podemos envidar os desafios do Ecohumanismo em que o ser humano, cônscio de sua missão no seio do planeta, pode assumir a responsabilidade de co-criador, de seu co-pertencimento planetário na condição de guardião e, quiçá, de jardineiro dessa morada planetária comum em que respiramos juntos. Para tanto, urge o cuidado terno e espirituoso, imbuído de altruísmo e de amorosidade.

A diversidade étnica que plasma a cultura humana representa a multiplicidade de valores que se revelam nas singularidades múltiplas de cada povo. Nesse contexto, os repertórios da Ética asseguram a relação de coexistência entre as diversidades como instância mediadora que, fundada em princípios considerados mais universais, buscam operar as relações dialógicas e tensivas de inclusividade e de reciprocidade entre as diferenças, identificando elos e elementos que unem e agregam os humanos - suas semelhanças em seus propósitos mais amplos e transcendentes. Nessa perspectiva, como acentua Carvalho (1999, p. 113), urge proporcionar "uma solidariedade transnacional articulada a uma ética dos direitos individuais" baseada num "ethos compreensivo" (CARVALHO, 1999, p. 111) que implica no cultivo da cumplicidade e da tolerância.

A Ética da coexistência se nutre, portanto, numa razão dialógica, comunicativa (Habermas) que interliga e promove o discernimento e a meditação inteligente (intus legere - ler de dentro). Uma razão marcada pela abertura e pela lucidez, que seja lúdica e sensível, e que, assim, plasma a consciência compreensiva lastreada no espírito altaneiro que se desdobra em generosidade, simpatia e cordialidade. Desse modo, podemos sair dos porões dos círculos viciosos que tanto corroem e desbotam a morada do humano, para os círculos virtuosos que nos enobrecem no zelo para com os valores humanos primordiais, como seiva que faz vicejar a amorosidade nos fluxos das relações intersubjetivas/sociais.

Inspirados e movidos pelos princípios fundantes da Ética da coexistência, de uma Ética ecocêntrica, podemos plasmar uma práxis humana que cuida com desvelo da terra-mátria-pátria, da terra frátria em que o espírito de solidariedade e de amorosidade entretecem a rede da complexidade dessa morada humana, ecohumana, forjando a Era das relações.

Entrelaçados pela in-tensidade dos abraços que nos fraternizam e nos ecofraternizam, podemos proporcionar relações 
ecológicas e ecossistêmicas de coexistência entre o bem, o verdadeiro da Ética, e o belo, a fineza da Estética: uma Ética planetária em que saímos da tecnosfera para a "ecosfera" (CARVALHO, 1999, p. 108), para a "Fraternidade cósmica" (Morin).

\section{A ação de educar como rito de iniciação à ética da coexistência}

A ação de educar, como práxis humana plasmada individual e coletivamente, pode ser compreendida com o ação que é articulada mediante processos in-tensivos de formação que proporcionam o desenvolvimento das sensibilidades crítico-criadoras, da consciência compreensiva, ética e estética de cada ser humano. Desse modo, ela se traduz na busca cuidadosa dos valores fundamentais que compõem a condição humana vislumbrando a compaixão do coração e o humanismo do espírito; num rito vivo de iniciação constante a esses valores, imersos nos contextos culturais em que os indivíduos rendam a teia do vivido/vivente, no dinamismo de seus fluxos mutantes.

Nessa perspectiva, o educar se configura na ação cuidadosa para com a inteireza do ser-sendo, na vastidão de sua complexidade transversal, em que os saberes e sentires são ruminados com sabor fomentando o cultivo da imaginação criante, do espírito compreensivo e inventivo e da sensibilidade amorosa.

As práticas educativas, em suas mais diversas formas de expressão, são travessias encampadas pelos humanos, na intensidade do transcurso sinuoso de suas trajetórias, através de processos contínuos e inacabados de aprendizados que conduzem às buscas de afinação do espírito e do coração nas fontes inesgotáveis da inteireza do ser-sendo-com.

Qualquer ação educativa, mesmo a auto-educação, ocorre mediante as relações de coexistência entre os indivíduos por meio dos processos de trocas e de aprendizados que emanam das relações tensivas e interativas entre os mesmos. Relações que são tingidas pelos mais diversos tons que perfazem a teia do humano: dores e prazeres, alegrias e tristezas, conflitos e contradições, permanências e mutações, sonhos e utopias, enfim, das trocas e partilhas dos valores e sentimentos, das crenças e idéias que desenham o Éthos dos indivíduos e dos grupos em suas expressões mais singulares e plurais. 
Desse modo, a ação de educar se instala e se desborda, no seio das práxis culturais, mediante a os fluxos dinâmicos das relações interpessoais e sociais em que seus conteúdos e métodos devem traduzir os repertórios da cultura viva e vivida pelos indivíduos. Ela é marcada e se nutre do Éthos, dos valores humanos que constituem os territórios da Ética, na perspectiva de afirmação e de expansão, de renovação e de transformação dos mesmos, de acordo com os compassos moventes da história humana.

O educar, portanto, em suas tonalidades polissêmicas, se configura como processo de formação e de iniciação aos valores que lastreiam a Ética e que proporcionam a práxis das relações de proximidade e de coexistência entre os seres humanos, na afirmação do espírito de solidariedade e de eqüidade, de fraternidade, de paz e de amorosidade.

O cotidiano das práxis educativas deve se traduzir em ritos de iniciação constantes aos saberes e sabedorias da cultura vivida/vivente, em que o corpo e o espírito estão visceralmente interligados, na sedimentação dos processos de aprendências e de co-aprendências que conduzem ao cuidado com os valores que afirmam a coexistência entre os seres, em suas singularidades e em suas diversidades.

A metáfora da roda se configura num símbolo bastante expressivo para representar a práxis educativa que vislumbra a Ética da coexistência. Na roda, todos se encontram frente a frente. Os olhares e os corações são interpelados para entrarem em relação de sintonia e de sinergia. Todos se encontram no mesmo nível espacial em que ninguém está atrás ou na frente de ninguém. Assim, cada um pode reconhecer a si mesmo e o outro, os outros, na afirmação da singularidade e da pluralidade, no compartilhar os sentimentos e os valores do altruísmo e da generosidade, da humildade e da compaixão.

Além disso, a roda também revela a composição da inteireza da vida, do ser, bordada pela multiplicidade de cores, relevos, sons e movimentos que, in-tensivamente se entrelaçam apontando para a relação primordial de busca da unidade na multipicidade; representa os movimentos cíclicos e a celebração da vida mediante as danças e cantigas das tradições populares enraizadas de sabedoria e que animam os indivíduos, seu existir e seu co-existir.

Imbuídos dessa consciência compreensiva que supõe abertura para a escuta e para a dialogia, podemos converter as quase 
sempre "celas de aula", em verdadeiras salas de aula - como também outros tantos espaços em que o educar acontece - marcadas pelas experiências vivificadoras dos ritos de iniciação e de celebração dos repertórios culturais e mitopoéticos que povoam o cotidiano dos indivíduos, através de vivências que tanto os afirmam como os renovam. Assim, podemos fortalecer as alianças que nos entrelaçam, nas riquezas de nossas diferenças, e que, portanto, nos conduzem aos processos de humanização e de fraternização, de ecohumanização e de ecofraternização.

Nessa perspectiva, urge ultrapassarmos as práticas educativas que predominantemente se apresentam como meros processos instrucionais, de transmissão e de reprodução de conteúdos e de técnicas, de modo frio e calculista, com posturas emboloradas e desvinculadas da seiva do vivido. Essas práticas projetam valores que incidem na competição e no individualismo que segregam e uniformizam. Os dispositivos técnicos e funcionais, os recursos didáticos - o ter -, devem ser canalizados como meios, como instrumentos que potencializam e proporcionam ações educativas que primam pelo cuidado com os valores humanos, com a formação e o aprendizado do saber ser consigo mesmo e ser-com-os-outros.

$\mathrm{Na}$ ação de educar, os processos meramente instrutivos e funcionais incidem na formação de papéis profissionais e sociais. Esses papéis, na dinâmica das relações sociais, também são significativos para os indivíduos, desde que os mesmos não sejam expropriados de sua condição primordial, da qualidade interna de sua condição humana, que não implique no descuidar da formação do seu ser-sendo-com. As práticas meramente instrutivas tendem a forjar seres mecânicos e frios, desprovidos de sensibilidade ética e estética. A mera formação técnica, tecnocientífica, que privilegia os papéis sociais externos, leva à desumanização dos indivíduos desembocando em posturas e atitudes individualistas e competitivas que incidem em processos de barbarização social e de esgarçamento de todo o ecossistema, como vimos anteriormente.

A presença dos princípios da Ética da coexistência na ação de educar preconiza processos de formação que consideram a inteireza dinâmica do ser-sendo, não apenas o pólo Ratio, do apolíneo, da razão analítica e da tecnociência, mas também e conjuntamente, o pólo Eros, do dionisíaco, da corporeidade, da sensibilidade poética numa relação de inclusividade fecundante. 
Sugere uma prática educativa que se nutre em experiências teóricas e reflexivas que fomentam o espírito crítico-criador dos indivíduos, mas também, e de modo implicado, em vivências em que o corpo, a sensibilidade, a imaginação criante florescem, considerando, portanto, os seres humanos na teia polifônica de sua inteireza.

Desse modo, o cuidado com a inteireza do humano se desdobra nas aprendências vivas que sedimentam o bem da Ética e o belo da Estética, a relação de co-implicação entre o corpo e o espírito, a busca do autoconhecimento, no cultivo da inteligência em seu sentido mais amplo: ler de dentro. O cultivo da coexistência entre o corpo (o sensível) e o espírito (o racional) proporciona a formação da inteireza in-tensiva do humano. A separação desses pólos interpolares empobrece e mutila desembocando em atitudes dilapidadoras.

A perspectiva da ação do educar como rito de iniciação na Ética da coexistência concebe que a compreensão e a vivência da lógica da inclusividade, da pedagogia do diálogo implicativo, despojado e acolhedor, são passos fundamentais para a superação da lógica da exclusividade - ainda predominante em nossas práticas educativas - que redunda nas intolerâncias e nos separatismos cruéis e barbarizantes. Supõe o cultivo dos valores da não-violência em que desarmamos nossos espíritos e nossos corpos para os encontros despojados mediante os abraços compassivos entre as alteridades, entre a diversidade humana. Assim, podemos fomentar as relações de simpatia e de empatia, os laços dialógicos que superam os monólogos e que afirmam a magnitude da diversidade de valores, das relações interculturais.

Dessa forma, de modo in-tensivo e desafiador, o local e o chamado global podem in-tensivamente se reconciliar e se abraçar na tecedura do glocal, promovendo e erguendo o estandarte da paz e da tolerância, da Ética da coexistência, da ecofraternização.

Nutridos nas fontes das sabedorias vividas e sedimentadas no Éthos que constitui a morada do humano - do glocal -, os processos de formação, de aprendências e de co-aprendências se traduzem em vivências compartilhadas e celebradas coletivamente, mediante as trocas enriquecedoras e inspiradoras do espírito de solidariedade, de amizade e de fraternização. Os compassos dessas aprendências fomentam a consciência compreensiva, o reconhecimento de si e do outro como seres interdependentes e 
complementares na teia das relações humanas e de todo o ecossistema. O aprendizado do ser-sendo-com-os-outros instaura os valores da honestidade e do altruísmo em que as máscaras do egoísmo, do individualismo e dos artifícios sociais dissimuladores podem ser diluídas e as relações podem se tornar mais implicadas e solidárias.

Na roda viva da ação de educar, o entrelace dinâmico e processual das diferenças de valores, crenças e sentimentos que constituem nosso ser-sendo-com, em suas ambigüidades e contradições, potencializa a ritualização das aprendências in-tensivas da simpatia e da empatia, em que os corações e os espíritos podem se abrir e se interligar na celebração do abraço que une e fortalece os sentimentos de solidariedade e de compaixão. Assim, as práxis educativas podem plasmar o aprendizado da auto-ética e da ecoética, da Ética da coexistência, no cuidado do ser-sendo de cada um consigo mesmo e do ser-com-os-outros, bem como, com todo o ecossistema; podem instituir os processos de religação que implicam na coexistência entre ciência e consciência, entre deveres e direitos, entre saber e sabedoria, entre os seres humanos e destes com a Natureza (Phýsis), entre o bem e o belo.

Os desafios desses processos de religação alicerçam a Ética planetária, o ecohumanismo, a eco-cidadania. Assim, podemos aprender a estabelecer, entre nós mesmos e com os outros seres do planeta, relações de admiração, de cumplicidade e de interdependência; relações de coexistência in-tensiva representadas pelo laço mestiço e amoroso do abraço que une, ecohumaniza e ecofraterniza.

\title{
Education as an initiation rite to the ethics of coexistence
}

\begin{abstract}
The text reflects about the supremacy of technoscientific and calculator rationility paradigms in our civilizatory process that, unprovided of Ethical contents, occur in separatist and destructive postures. It treats the Ethics like the care with the human housing with the human values. It treats the coexistence Ethics molded in the carefulness towards the social and intersubjective relations and of the human being toward all the beings of the universe: the eco-ethics. Comprehend the action of educate as a live rite of iniciation of the humans values, of the care with the auto-ethics, of the ecoethics; of the Ethics of coexistence. Thus, foment relations more fraternal and solidary, lovely and interdependent in the refinement of the compassion of the heart and of the humanism of the spirit.

KEY WORDS: Educative action. Ethics. Humanistic education. Human values.
\end{abstract}




\section{Referências}

ARAÚJO, Miguel Almir de. Laços de encruzilhada: ensaios transdisciplinares. Feira de Santana, BA:, UEFS, 2002.

ARISTÓTELES. Ética a Nicômaco: poética. São Paulo: Nova Cultural, 1987. (Pensadores; 2).

BOFF, Leonardo. Saber cuidar: ética do humano: compaixão pela terra. Petrópolis, RJ: Vozes, 1999.

BUBER, Martin. Eu e tu. São Paulo: Moraes, 1974.

CARVALHO, Edgar de Assis. Complexidade e ética planetária. In: PENA-VEGA, Alfredo; NASCIMENTO, Elimar P. do. O pensar complexo: Edgar Morin e a crise da modernidade. Rio de Janeiro: Garamond, 1999.

CARVALHO, Edgard de Assis et al. Ética, solidariedade e complexidade. São Paulo: Palas Athena, 1998.

DISKIN, Lia et al. Ética, valores humanos e transformação. São Paulo: Fundação Peirópolis, 1998.

MAFFESOLI, Michel. O tempo das tribos: o declínio do individualismo nas sociedades de massa. Rio de Janeiro: Forense Universitária, 1987.

MORIN, Edgar. Amor poesia sabedoria. Rio de Janeiro: Bertrand Brasil, 1998.

MORIN, Edgar. Ciência com consciência. Rio de Janeiro: Bertrand Brasil, 1999.

MORIN, Edgar. A terra como pátria. Revista Thot, São Paulo, n. 63, p. 38-41, 1996.

NOVAES, Adauto (Org.). Ética. São Paulo: Companhia das Letras: Secretaria Municipal de Cultura, 1992.

VAZ, Henrique C. de Lima. Escritos de Filosofia II: ética e cultura. São Paulo: Loyola, 1993. 